\title{
Cefepime-induced neurotoxicity
}

\section{Se-Jin Lee, MD, PhD}

Department of Neurology, Yeungnam University College of Medicine, Daegu, Republic of Korea

\section{Journal of Neurocritical Care}

\section{REVIEW ARTICLE}

Received: November 4, 2019

Revised: December 9, 2019

Accepted: December 9, 2019

Corresponding Author:

Se-Jin Lee, MD, PhD

Department of Neurology, Yeungnam University College of Medicine, 170

Hyeonchung-ro, Nam-gu, Daegu

42415, Republic of Korea

Tel: +82-53-620-3683

Fax: +82-53-627-1688

E-mail: sejinmayo@ynu.ac.kr

Cefepime, a widely used fourth-generation cephalosporin, has been reported to cause neurotoxicity because it crosses the blood-brain barrier. Although cefepime-induced neurotoxicity (CIN) occurs in patients with renal dysfunction administered a high dosage, CIN has also been reported in patients with normal renal function administered the appropriate dosage. CIN is characterized by toxic encephalopathy and electroencephalography abnormalities, such as triphasic wave, currently renamed as generalized periodic discharge (GPD) with triphasic morphology, and nonconvulsive status epilepticus (NCSE). Toxic encephalopathy appears 2 to 6 days after cefepime administration and disappears 3 days after discontinuation of cefepime. Electroencephalography abnormalities in most reported cases are GPD with triphasic morphology rather than NCSE. CIN is reversible in most cases if early detection and discontinuation of cefepime is possible, which is the only definitive treatment; however, anticonvulsant therapy is unnecessary except for patients with convulsive seizures or definite NCSE. Emergent hemodialysis may also be helpful in life-threatening situations.

Keywords: Cefepime; Neurotoxicity syndromes; Generalized periodic discharges; Triphasic waves; Nonconvulsive status epilepticus

\section{INTRODUCTION}

Cefepime, a fourth-generation cephalosporin antibiotic, was approved for use in 1996. It is widely used to treat severe bacterial infections because it acts against both gram-negative and gram-positive bacterial strains, and has antipseudomonal activity. Safety data of cefepime in clinical trials were relatively favorable when initially approved. Approximately $3 \%$ of 2,032 patients treated with cefepime experienced adverse central nervous system (CNS) effects including headache (2.4\%), dizziness (0.7\%), and insomnia (0.6\%) [1]. Eleven (0.2\%) patients developed seizures but only three $(0.1 \%)$ of these cases were considered to have a probable or unknown relationship to cefepime therapy [1].

Cefepime-induced neurotoxicity (CIN) was first reported in a patient with end-stage renal disease (ESRD) on hemodialysis in 1999 [2]. He developed altered mental status, myoclonus, and a generalized tonic-clonic seizure with elevated serum cefepime concentration. He recovered after urgent hemodialysis but electroencephalography (EEG) was not performed. Thereafter many cases of CIN with triphasic wave (TW) or nonconvulsive status

(C) 2019 The Korean Neurocritical Care Society

This is an Open Access article distributed under the terms of the Creative Commons Attribution Non-Commercial License (http://creativecommons.org/licenses/by-nc/4.0/) which permits unrestricted noncommercial use, distribution, and reproduction in any medium, provided the original work is properly cited. 
epilepticus (NCSE) have been reported. CIN is composed of toxic encephalopathy and TW or NCSE in EEG. There is debate about EEG findings regarding whether it is true NCSE or TW.

CIN mainly occurs in patients with impaired renal function who have been administered cefepime without dose adjustment, because $85 \%$ of cefepime is removed through renal excretion [3-11]. However, it has also occurred in patients who have received appropriate doses based on renal function [12-18] and even in patients with normal renal function [5,18-22]. Therefore, the U.S. Food and Drug Administration (FDA) issued a safety warning that recommended dose reduction in patients with renal dysfunction, that is, estimated glomerular filtration rate (GFR) $<60 \mathrm{~mL}$ / $\min$ [23]. CIN is reversible in most cases if early detection and discontinuation of cefepime is possible, which is the only definitive treatment. Frequent neurologic examination and monitoring of renal function are needed, especially in the elderly with impaired renal function or previous CNS injury.

After a review of cases, case series, and meta-analysis, we have described the incidence, pathogenic mechanism, risk factors, clinical manifestation, EEG abnormalities, and appropriate management of CIN. We have also analyzed all the cases of CIN reported in the Korean medical literature.

\section{INCIDENCE}

The reported incidence of $\mathrm{CIN}$ is quite variable because of differences in the diagnostic criteria of CIN, the protocol for dose adjustment of cefepime, degree of renal dysfunction, characteristics of included patients, and severity of underlying illness or comorbidity. In addition, small sample size and retrospective study design are also likely to influence the results.

In a prospective cohort study, the incidence of $\mathrm{CIN}$ in patients with medical illness was 1\%; however, in patients with GFR 60 to $15 \mathrm{~mL} / \mathrm{min}$ and GFR $<15 \mathrm{~mL} / \mathrm{min}$, CIN incidence increased to $4.5 \%$ and $16.6 \%$, respectively [4]. Incidence in critically ill patients [6] and in patients with hematologic malignancies [24] was $15 \%$ and $4.1 \%$. The incidence of CIN in a retrospective case-control study in Korean patients was 0.85\% [25]. The incidence in ESRD patients was $7.5 \%$, but was $22.2 \%$ in ESRD patients with preexisting CNS morbidity [17]. In a recent retrospective study, the incidence of CIN was $0.2 \%$ [9].

Therapeutic drug monitoring (TDM) studies show that the incidence of CIN has increased, from $11 \%$ to $23.2 \%$ [26-28]. In the French pharmacovigilance database on serious CNS adverse effects, cefepime was the most common drug among cephalosporins to be associated with CNS adverse effects [29].

The incidence of CIN was higher immediately after the approv- al of cefepime than that in recent times, because initially dose adjustment was recommended for patients with impaired renal function when the GFR was $<50 \mathrm{~mL} / \mathrm{min}$ by the manufacturer [30]. Furthermore, the physicians were not exactly aware of the clinical manifestations and risk factors of CIN. Therefore, many cases of CIN might have occurred in hospitals where cefepime was widely used, as in Geneva Cantonal Hospital [31].

\section{PHARMACOLOGY}

Cefepime has a low molecular weight of 480.6 daltons and is known to display linear (first-order) pharmacokinetics regardless of the treatment duration [32]. Serum protein binding of cefepime is approximately $20 \%$ and is independent of its concentration in serum.

\section{Renal excretion and half life}

In normal subjects, the total body clearance of cefepime is dose-independent. Urinary excretion of unchanged cefepime accounts for approximately $85 \%$ of the administered dose [32]. Therefore, the cefepime dosage should be reduced according to renal function in patients whose GFR is $\leq 60 \mathrm{~mL} / \mathrm{min}$ [33]. The half-life in healthy volunteers is 2 hours whereas that in patients with ESRD requiring hemodialysis is 13.5 hours and that in patients requiring continuous ambulatory peritoneal dialysis (CAPD) is 19 hours $[33,34]$.

\section{Hepatic metabolism}

Only a small proportion of cefepime is metabolized to N-methylpyrrolidine (NMP) which is rapidly converted to $\mathrm{N}$-oxide (NMP-N-oxide) [35]. Less than $1 \%$ of the administered dose is recovered from urine as NMP. The pharmacokinetics of cefepime were unaltered in patients with hepatic impairment who received a single $1 \mathrm{~g}$ dose.

\section{PATHOGENIC MECHANISMS}

Although the pathophysiology of CIN is not fully understood, it is supposed to be related to the concentration dependent competitive inhibition of $\gamma$-aminobutyric acid (GABA) A receptors in animal studies [36]. Cephalosporins may also decrease GABA release from nerve terminals or increase excitatory amino acid release [37]. Through these mechanisms, cefepime treatment results in hyperexcitation of neurons and depolarization of the postsynaptic membrane, which are consistent clinically with the occurrence of seizures, myoclonus, and encephalopathy. 


\section{RISK FACTORS OF CIN}

Impaired renal function and excessive dose are the most important and common predisposing factors of CIN. Preexisting brain injury, old age, high-dose therapy, and increased CNS penetration of cefepime are known risk factors $[6,9,10,17,38]$. However, CIN has also been reported in patients with normal renal function $[5,18-22,39,40]$ and in those administered the appropriate dose based on renal function [12-18,41-43]. The cause of CIN in these patients is not known.

\section{Renal dysfunction}

A meta-analysis revealed that 80 to $87 \%$ of patients with CIN had renal dysfunction $[9,10]$. In patients with renal failure, cerebrospinal fluid (CSF) concentrations of cefepime may increase due to competitive inhibition of active transport of cefepime from CSF to blood by organic acids [44], an increase in blood-brain barrier (BBB) permeability, and a decrease in serum protein binding [45]. Moreover, renal function may be overestimated by the Cockroft-Gault formula under debilitating conditions such as malnutrition and amyotrophy [26]. Thus, an excessive dose of cefepime may be administered.

\section{Excessive dosing}

The results of a meta-analysis showed that $25 \%$ to $50 \%$ of patients with CIN received an excessive dose of cefepime. This may be due to either failure of dose adjustment or miscalculation of dosage.

\section{Preexisting brain injury}

CNS penetration of cefepime may be increased in patients with a previous brain injury. The incidence of CIN in ESRD patients with preexisting CNS morbidity was $22.2 \%$, which is three times higher than that in ESRD patients without previous CNS injury [17]. From the data of a meta-analysis, $8 \%$ of the reported patients had preexisting CNS disease [10].

\section{Old age}

Most of the reported patients were of old age, with a median of 69 years, ranging from 54 to 75 years [10]. The elderly are thus susceptible to renal dysfunction and CNS adverse effects.

\section{Increased CNS penetration}

In patients with sepsis, CNS infection, uremia, and previous brain injury, $\mathrm{BBB}$ integrity may be disrupted, resulting in increased CNS penetration of cefepime up to $45 \%$, which is much higher than the $10 \%$ in normal conditions $[46,47]$. Blood levels of unbound cefepime, which is the biologically active fraction of cefepime avail- able for entry into the CNS, are increased in patients with hypoalbuminemia due to renal or hepatic dysfunction [45].

\section{Patients with adjusted dose or normal renal function}

Quarter to half of patients with CIN appeared to receive an appropriate dosage according to their renal function $[9,10]$. CIN occurrence in patients with adjusted dose or normal renal function may be due to the following reasons: (1) individual variations in pharmacokinetics or pharmacodynamic susceptibility [9]; (2) although renal function was normal before initiation of cefepime treatment, renal dysfunction may occur during cefepime treatment due to aggravation of systemic conditions and nephrotoxicity of combined medications such as aminoglycosides $[4,45,46,48,49]$; (3) competitive inhibition of active transport of cefepime from CSF to blood. An increase in BBB permeability, hypoalbuminemia, and a decrease in serum protein binding may act as provocative factors.

\section{DOSE ADJUSTMENTS}

Cefepime dose should be adjusted based on current renal function (Table 1). Normal renal function is defined as a creatinine clearance of $60 \mathrm{~mL} / \mathrm{min}$ [23]. Moreover, the physician needs to take into account age, preexisting brain injury, hypoalbuminemia, and septic conditions.

In patients with severe infection or critical illness, dose adjustment according to serum cefepime levels may be helpful. Dose adjustment is not necessary in patients on continuous renal replacement therapy (CRRT) [2,50]. However, it is reasonable to consider the severity of the infectious disease during dose adjustment to prevent treatment failure [17].

\section{SERUM CEFEPIME CONCENTRATION}

Some investigators measured serum cefepime concentrations and demonstrated the association between serum cefepime concentrations and the occurrence of $\operatorname{CIN}[28,45,51]$. Others described that clinical improvement of CIN was associated with a decrease in the blood concentration of cefepime $[2,26,45,46]$.

Although the target serum trough concentrations of cefepime have not been well established, the neurotoxic threshold may be around $20 \mathrm{mg} / \mathrm{L}$ based on the data of published reports, and interpersonal variability is observed $[26,27,52]$. TDM may be useful to avoid neurotoxicity, especially in patients with high-dose therapy, renal dysfunction, and on CRRT. 
Table 1. Recommended dosing schedule of cefepime based on renal function in adults

\begin{tabular}{|c|c|c|c|c|}
\hline \multirow{2}{*}{$\mathrm{CrCl}(\mathrm{mL} / \mathrm{min})$} & \multirow{2}{*}{$\left.\mathrm{UTI}\right|^{\mathrm{a})}$} & \multicolumn{3}{|c|}{ Pneumonia ${ }^{b)}$} \\
\hline & & UTI $^{\text {a) }}$, pneumonia ${ }^{\text {b) }}$ & $\mathrm{UTI}^{\mathrm{c}}, \mathrm{SSSI}^{\mathrm{d})}$, intra-abdominal $\left.\right|^{\mathrm{e})}$ & Febrile $^{\text {f) }}$ neutropenia \\
\hline$>60$ & $500 \mathrm{mg} \mathrm{q} 12 \mathrm{hr}$ & $1 \mathrm{~g} \mathrm{q} 12 \mathrm{hr}$ & $2 \mathrm{~g} \mathrm{q} 12 \mathrm{hr}$ & $2 \mathrm{~g} \mathrm{q} 8 \mathrm{hr}$ \\
\hline $30-60$ & $500 \mathrm{mg} \mathrm{q} 24 \mathrm{hr}$ & $1 \mathrm{~g} \mathrm{q} 24 \mathrm{hr}$ & $2 \mathrm{~g} \mathrm{q} 24 \mathrm{hr}$ & $2 \mathrm{~g} \mathrm{q} 12 \mathrm{hr}$ \\
\hline $11-29$ & $500 \mathrm{mg} \mathrm{q} 24 \mathrm{hr}$ & $500 \mathrm{mg} \mathrm{q} 24 \mathrm{hr}$ & $1 \mathrm{~g} \mathrm{q} 24 \mathrm{hr}$ & $2 \mathrm{~g} \mathrm{q} 24 \mathrm{hr}$ \\
\hline$<11$ & $250 \mathrm{mg} \mathrm{q} 24 \mathrm{hr}$ & $250 \mathrm{mg} \mathrm{q} 24 \mathrm{hr}$ & $500 \mathrm{mg} \mathrm{q} 24 \mathrm{hr}$ & $1 \mathrm{~g} \mathrm{q} 24 \mathrm{hr}$ \\
\hline CAPD & $500 \mathrm{mg} \mathrm{q} 48 \mathrm{hr}$ & $1 \mathrm{gq} 48 \mathrm{hr}$ & $2 \mathrm{~g} \mathrm{q} 48 \mathrm{hr}$ & $2 \mathrm{~g} \mathrm{q} 48 \mathrm{hr}$ \\
\hline Hemodialysis $^{g)}$ & $\begin{array}{c}1 \mathrm{~g} \text { on day } 1 \text {, then } 500 \mathrm{mg} \mathrm{q} \\
24 \mathrm{hr} \text { thereafter }\end{array}$ & $\begin{array}{c}1 \mathrm{~g} \text { on day } 1 \text {, then } 500 \mathrm{mg} \mathrm{q} \\
24 \mathrm{hr} \text { thereafter }\end{array}$ & $\begin{array}{c}1 \mathrm{~g} \text { on day } 1 \text {, then } 500 \mathrm{mg} \mathrm{q} \\
24 \mathrm{hr} \text { thereafter }\end{array}$ & $1 \mathrm{~g} \mathrm{q} 24 \mathrm{hr}$ \\
\hline
\end{tabular}

$\mathrm{CrCl}$, creatinine clearance; UTI, urinary tract infection; SSSI, skin and skin structure infection; q, qua; CAPD, continuous ambulatory peritoneal dialysis.

${ }^{\text {a) }}$ For mild-to-moderate uncomplicated or complicated UTIs including pyelonephritis; ${ }^{b)}$ For moderate-to-severe pneumonia; ${ }^{\mathrm{c}}$ For severe uncomplicated or complicated UTIs including pyelonephritis; ${ }^{\text {d) }}$ For moderate-to-severe uncomplicated SSSIs; ${ }^{\text {e) }}$ For complicated intraabdominal infections when used with metronidazole; ${ }^{f)}$ Empirical therapy for febrile neutropenia; ${ }^{g}$ Cefepime should be administered after hemodialysis on hemodialysis days.

\section{CLINICAL AND EEG MANIFESTATIONS}

Clinical manifestations are composed of toxic encephalopathy including altered mental status, tremor, myoclonus, and seizure, and EEG abnormalities comprise generalized periodic discharge (GPD), TW, or NCSE.

\section{Symptoms of encephalopathy}

From the data of a recent meta-analysis $[9,10]$, clinical symptoms include depressed consciousness, disorientation, aphasia, tremor, and myoclonus. Depressed consciousness ( $47 \%$ or $80 \%$ ) includes drowsiness, stupor, or coma, and disorientation comprising confusion, delirium, and agitation. Although the main clinical feature is encephalopathy, $\mathrm{CIN}$ is a heterogeneous syndrome.

Patients develop altered mental status, which usually occurs within 4 days (2 to 6 ) after cefepime administration $[9,10]$. The latency may depend on the serum or CSF concentrations of cefepime, which are associated with the dosage of cefepime, status of renal function, CNS penetration, and individual variation in pharmacokinetics.

Clinical improvement and resolution of EEG abnormalities were observed within 2 days ( 1 to 3 ) after discontinuation of cefepime [10].

\section{Seizures and NCSE}

In about a third of the reported cases, electrographic NCSE without abnormal behavior suggestive of seizure was reported [9]; however, convulsive seizures were extremely rare $[2,4,6,10$, $14,17,43]$. Many patients with CIN develop myoclonus and severe myoclonus may look like a clonic seizure [6].

\section{TW or NCSE, which is true?}

TW, currently renamed as GPD with triphasic morphology [53], is a descriptive term based on morphology and is traditionally associated with hepatic and uremic encephalopathy. Now, it is well known that GPD with triphasic morphology can be observed in a wide range of encephalopathies. It has been suggested that GPD is associated with the development of electrographic seizure; however, the clinical significance of GPD and its relationship with seizures has been debated [54].

GPD appears in other toxic encephalopathies such as serotonin syndrome and valproate-induced hyperammonemic encephalopathy, and in drug intoxication by lithium, baclofen, levodopa, pentobarbital, tiagabine, pregabalin, levetiracetam, or ifospamide [5563].

EEG abnormalities in the reported cases of CIN comprise two patterns, slow typical TW with triphasic morphology at $1 \mathrm{~Hz}$ with background slowing, and fast atypical TW with triphasic morphology may represent "TW look-alikes" such as with drug intoxication by lithium, baclofen, levodopa, pregabalin, and tiagabine (Fig. 1) [64]. The latter pattern is difficulty to differentiate from NCSE and many investigators interpret it as NCSE.

Diagnosis of NCSE should be strictly relied on the current working clinical criteria [65] and the standardized terminology of the American Clinical Neurophysiology Society (ACNS) [53]. Definite NCSE in comatose patients may be regarded as proven, if both the EEG and clinical state resolves with antiepileptic drug (AED) treatment $[65,66]$. Regardless of the etiology and pathophysiology, advanced coma stages are frequently accompanied with continuous epileptiform or periodic abnormalities [67]. It had been suggested that continuous epileptiform EEG in patients with encephalopathy may be an epiphenomenal character [68] and continuous epileptiform patterns found in advanced coma stage may represent an end-stage of irreversible coma, as in anoxic brain injury $[67,69]$.

For the same or quite similar clinical symptoms and EEG ab- 
A

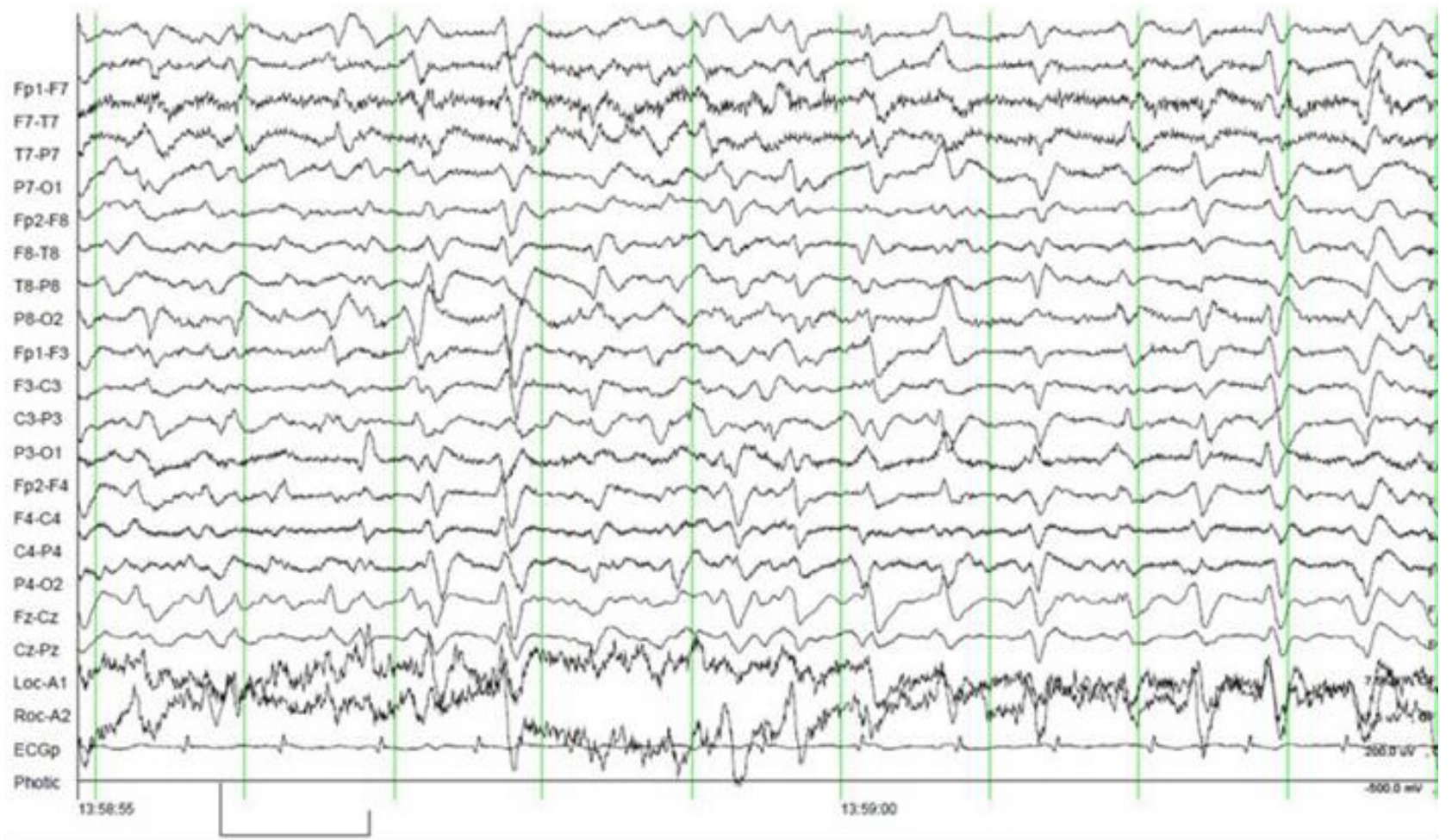

B

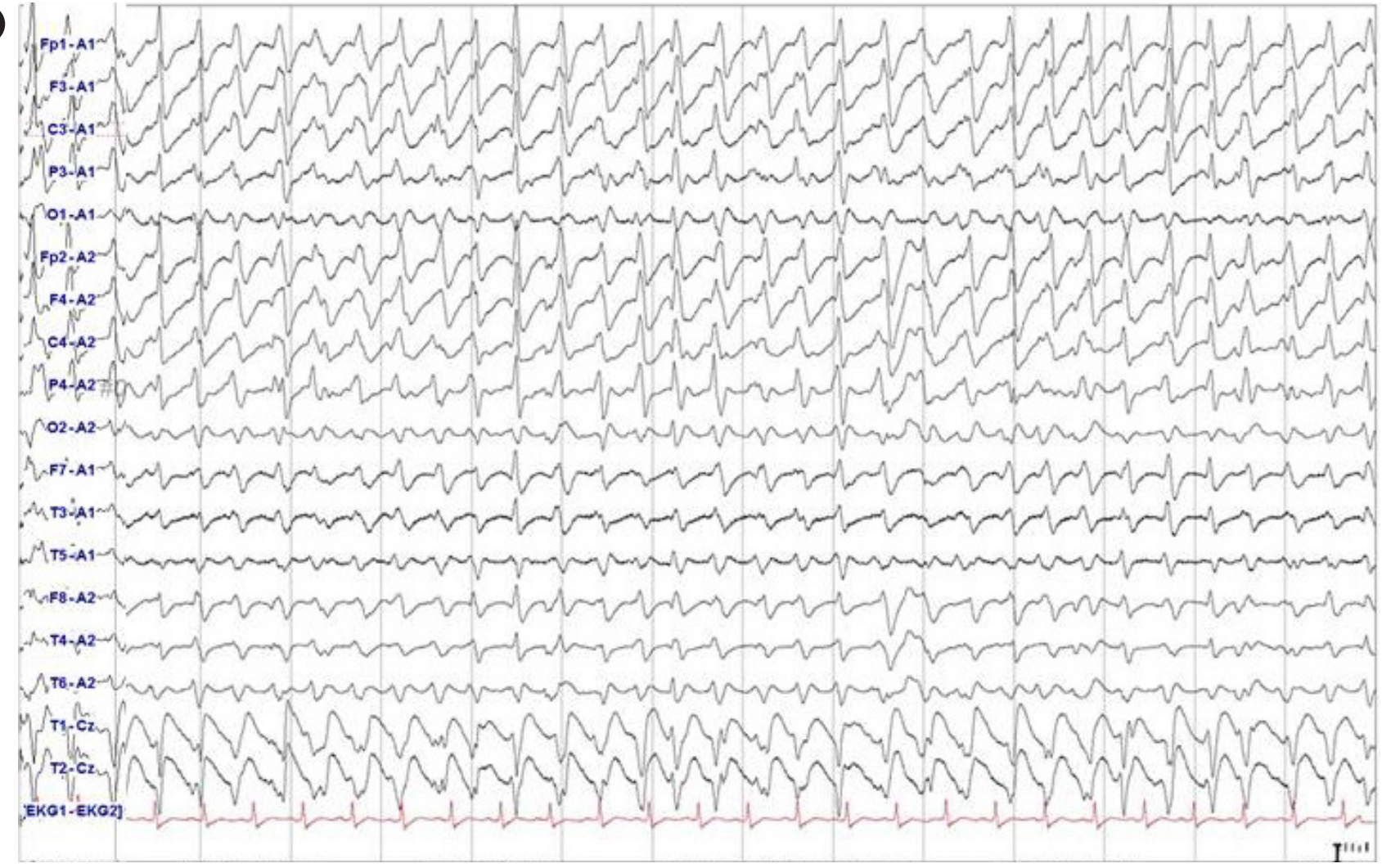

Fig. 1. Example of triphasic wave (TW) pattern in patients with cefepime-induced neurotoxicity. Electroencephalography showing slow, typical TW (A) and fast, atypical TW (B), "TW look-alikes"; the latter is difficult to differentiate from nonconvulsive status epilepticus. (A) Modified from Baek et al. [41], according to the Creative Commons License; (B) is a personal case of the author. 
normalities, some described as CIN with TW or GPD $[3,15$, 17,22,24,43,49,70-76], whereas others reported these as CIN with NCSE [4-6,13,14,16,18,20,21,42,45,77-84], depending on the author's view. Some investigators proposed that encephalopathies with GPD or severe metabolic encephalopathies with continuous epileptiform EEG abnormality are not NCSE, and that a coma with continuous generalized epileptiform discharges (coma-GED) should be differentiated from NCSE proper $[67,69]$.

The FDA released drug safety communications about the risk of seizure, which included 59 cases of NCSE associated with cefepime from the approval of cefepime in 1996 to 2012 [23]. However, recently Triplett et al. [43] analyzed 37 EEG samples of CIN cases reported in the literature as NCSE $(n=30)$ or TW $(n=7)$, and reported that most EEG did not satisfy the working criteria for NCSE, with 33 showing TW, one showing GEDs, and three being uninterpretable. They concluded that most cases of electrographic NCSE in the literature may be a misinterpretation of continuous GPD as follows. First, their EEG did not satisfy the working clinical criteria for NCSE [65]. Most of the reported cases showed transient or partial improvement of EEG after intravenous administration of benzodiazepines [13,21,44,48,70,77,83]; however, GPD with triphasic morphology can be also suppressed by intravenous benzodiazepines $[43,85,86]$. Immediate clinical improvement occurred exceptionally in few cases $[20,76,81]$. Second, most patients recovered after discontinuation of cefepime alone; furthermore, rapid elimination of cefepime through hemodialysis markedly sped their recovery compared with anticonvulsant therapy, from 2 to 1 day $[2,10,14,45,74,82]$. Third, if EEG abnormalities in patients with CIN indicate true NCSE, anticonvulsant therapy hastens clinical improvement [43,76]; however, AED was not effective in the recovery of EEG and clinical symptoms [10].

\section{DIAGNOSIS}

The diagnostic criteria used in the literature are defined as follows: (1) neurological symptoms emerging several days after initiation of cefepime treatment; (2) accompanying EEG findings are consistent with GPD with triphasic morphology; (3) symptoms and abnormal EEG resolved within several days after discontinuation of cefepime; (4) no other cause of toxic or metabolic encephalopathy that is likely to be the cause of altered mental status; and (5) abnormally increased serum concentrations of cefepime if available $[4,6,9,10,17,43,76]$.

High index of suspicion is very important in the early diagnosis of CIN, especially in patients with risk factors or new onset of altered mental status after initiation of cefepime. Thus, frequent monitoring of renal function and mental status, recording of EEG, and measurement of serum levels of cefepime appear to be of value in patients with risk factors of CIN.

CIN may sometimes be difficult to diagnose since critically ill patients often present comorbidities or comedications that could at least partially account for the neurological symptoms.

\section{MANAGEMENT}

\section{Discontinuation of cefepime}

The only definite treatment of CIN is discontinuation of cefepime. The result of a meta-analysis revealed that the most common intervention was withdrawal (81\%) or interruption of treatment with reduction of cefepime dosage (4\%), which led to clinical recovery or improvement within 1 to 3 days in about $90 \%$ of the patients [10].

\section{Dialysis}

Hemodialysis rapidly removes cefepime from blood and CSF and hastens recovery, especially in life-threatening situations. There have been several reports of emergent hemodialysis with successful results $[2,6,14,41,45,46,74,82]$.

Meta-analysis showed that $8 \%$ or $14 \%$ of the cases received hemodialysis $[9,10]$. Hemodialysis resulted in more rapid recovery of encephalopathy and disappearance of GPD than those observed in the AED group, and the median time to clinical improvement dropped from 2 to 1 day [10].

A single 3-hour hemodialysis session is efficient to remove 70\% of a given dose due to the low protein binding, low molecular weight, and low volume distribution of cefepime [33]. Hemodialysis reduces the elimination half-life of cefepime from 13.5 to 2.3 hours in patients with ESRD requiring hemodialysis.

CAPD is much less efficient in clearing cefepime with only $9 \%$ of the cefepime clearance in hemodialysis [34].

CRRT also easily removes cefepime from blood, and is more effective than CAPD but less so than hemodialysis [87].

\section{Anticonvulsants}

A meta-analysis revealed that a third of the reported cases received anticonvulsants including benzodiazepines, phenobarbital, phenytoin, levetiracetam, and valproic acid $[9,10]$. Although EEG showed temporary suppression of GPD after intravenous injection of benzodiazepine, there was no immediate and permanent recovery of mental status or EEG. Clinical and EEG recovery within 2 to 3 days of intervention is related to discontinuation of cefepime rather than anticonvulsant therapy $[10,43,76]$. Therefore anticonvulsant therapy is not warranted anymore for the treatment of CIN except for patients with convulsive seizures 
Table 2. Nine cases of cefepime-induced neurotoxicity reported in Korea

\begin{tabular}{|c|c|c|c|c|c|c|c|c|c|}
\hline Study & Age/sex & $\begin{array}{c}\text { Renal } \\
\text { dysfunction }\end{array}$ & Dose (g) & Clinical symptoms & $\begin{array}{l}\text { Latency } \\
\text { (day) }\end{array}$ & $\begin{array}{l}\text { Improvement } \\
\text { after Tx (day) }\end{array}$ & $\begin{array}{c}\text { EEG } \\
\text { description }\end{array}$ & Treatment & Remark \\
\hline Ryu et al. [49] & $84 / \mathrm{M}$ & Yes & $\begin{array}{c}2 \text { bid } \\
\text { (excessive) }\end{array}$ & $\begin{array}{l}\text { Confusion, stupor, } \\
\text { myoclonus }\end{array}$ & 3 & 2 & TW at $1.5 \mathrm{~Hz}$ & $\begin{array}{l}\text { AED for } \\
\text { myoclonus }\end{array}$ & GPD at $1.5 \mathrm{~Hz}$ \\
\hline Ryu et al. [49] & $74 / F$ & Yes & $\begin{array}{c}2 \text { bid } \\
\text { (adjusted) }\end{array}$ & Confusion & 2 & 7 & TW & & No EEG sample \\
\hline Baek et al. [41] & $71 / F$ & Yes & $\begin{array}{c}2 q d \\
\text { (adjusted) }\end{array}$ & Agitation, stupor & 3 & 3 & TW at $1.5 \mathrm{~Hz}$ & $\mathrm{HD}$ & Albumin $1.9 \mathrm{~g} / \mathrm{L}$ \\
\hline Lee et al. [42] & $68 / \mathrm{F}$ & Yes (HD) & $\begin{array}{c}? \\
\text { (adjusted) }\end{array}$ & & 6 & NA & NCSE & AED & GPD at $2 \mathrm{~Hz}$ \\
\hline Kim et al. [88] & $71 / F$ & Yes (CRRT) & $\begin{array}{c}2 \text { bid } \\
\text { (adjusted) }\end{array}$ & Stupor, myoclonus & 5 & 3 & NCSE & AED & GPD at $2 \mathrm{~Hz}$ \\
\hline Kim et al. [39] & $75 / \mathrm{M}$ & No & $\begin{array}{c}2 \text { tid } \\
\text { (appropriate) }\end{array}$ & Drowsy, tremor & 2 & 2 & & & $\begin{array}{l}\text { EEG- } \\
\text { uninterpretable }\end{array}$ \\
\hline Kwon et al. [89] & $36 / \mathrm{M}$ & Yes & $\begin{array}{c}2 \text { tid } \\
\text { (excessive) }\end{array}$ & $\begin{array}{l}\text { Global aphasia } \\
\text { Rt hemiplegia }\end{array}$ & NA & 2 & $\begin{array}{l}\text { NCSE } \\
\text { (continuous } \\
\text { SW at } 2.5 \\
\mathrm{~Hz} \text { on the Lt } \\
\text { frontal) }\end{array}$ & & $\begin{array}{l}\text { Old structural } \\
\text { lesion and } \\
\text { continuous SWs } \\
\text { at the Lt frontal } \\
\text { area }\end{array}$ \\
\hline Lee [90] & $31 / \mathrm{M}$ & Yes (HD) & $\begin{array}{c}2 \text { tid } \\
\text { (excessive) }\end{array}$ & Stupor, myoclonus & 4 & 5 & NCSE & & GPD at 2 to $3 \mathrm{~Hz}$ \\
\hline Park et al. [40] & $74 / F$ & No & $\begin{array}{c}2 \text { bid } \\
\text { (appropriate) }\end{array}$ & Stupor, myoclonus & 6 & 4 & NCSE & AED & GPD at $2 \mathrm{~Hz}$ \\
\hline
\end{tabular}

Tx, treatment; EEG, electroencephalography; bid, twice a day; TW, triphasic wave; AED, antiepileptic drug; GPD, generalized periodic discharge; qd, daily; HD, hemodialysis; NA, not available; NCSE, nonconvulsive status epilepticus; CRRT, continuous renal replacement therapy; Rt, right; SW, spike-wave; Lt, left.

or definite NCSE $[43,76]$.

\section{ANALYSIS OF KOREAN CASES}

There have been nine case reports of CIN in Korean medical journals (Table 2) [39-42,49,88-90]. Six of the nine were diagnosed as NCSE $[39,40,42,88-90]$ and four received anticonvulsants; however, three cases were described as CIN with TW or GPD [39,41] and did not receive anticonvulsants. In the eight EEG samples of the nine reported cases (no EEG in one case [49]), six showed GPD with triphasic morphology at 2 to $3 \mathrm{~Hz}$. One had symptomatic aphasic status epilepticus associated with a preexisting brain injury and cefepime intoxication, and the other showed uninterpretable EEG [39].

\section{PREVENTION}

Prevention of CIN is the best treatment. For prevention, adjustment of dosage is most important when renal function is impaired or the serum level of cefepime is abnormally increased. Careful monitoring of renal function is recommended to allow daily adjustment of the cefepime dose. TDM of cefepime can be helpful if available.

\section{PROGNOSIS}

An early diagnosis and discontinuation of cefepime is a major key to a favorable outcome. CIN is reversible in most patients. Death may occur due to underlying illness or a delay in diagnosis. Unexplained mortality in patients with CIN has been reported many times, although a causal relationship between neurotoxicity and mortality has not been demonstrated [71,91]. The FDA reported that a statistically significant increased mortality in patients on cefepime compared to that in patients on other cephalosporines was not identified upon meta-analysis [92].

\section{CONCLUSION}

CIN is a toxic encephalopathy with GPD in most cases rather than NCSE, which usually occurs at 2 to 5 days after cefepime initiation and improves in 1 to 3 days after discontinuation. For prevention of CIN, dose adjustment according to renal function is essential in patients with renal insufficiency, and then, careful monitoring of renal function and neurological status is required. CIN should be suspected when new onset of acute neurological deficits occurs in patients with risk factors of CIN. However, CIN may also occur in patients with normal renal function and adjusted dose based on renal function. A diagnosis of $\mathrm{CIN}$ can be made after excluding other 
causes of altered mental status, supported by GPD on EEG or increased serum levels of cefepime. CIN is reversible after prompt discontinuation of cefepime, and in life-threatening situations, emergent hemodialysis may be helpful. Anticonvulsant therapy is necessary only for patients with convulsive seizures or definite NCSE.

\section{ARTICLE INFORMATION}

\section{Conflict of interest}

No potential conflict of interest relevant to this article.

\section{ORCID}

Se-Jin Lee, https://orcid.org/0000-0001-7438-691X

\section{Author contributions}

Conceptualization: SJL. Data curation \& Formal analysis: SJL. Visualization \& Writing-original draft: SJL. Writing-review editing: SJL.

\section{REFERENCES}

1. Neu HC. Safety of cefepime: a new extended-spectrum parenteral cephalosporin. Am J Med 1996;100(6A):68S-75S.

2. Wong KM, Chan WK, Chan YH, Li CS. Cefepime-related neurotoxicity in a haemodialysis patient. Nephrol Dial Transplant 1999; 14:2265-6.

3. Jallon P, Fankhauser L, Du Pasquier R, Coeytaux A, Picard F, Hefft $S$, et al. Severe but reversible encephalopathy associated with cefepime. Neurophysiol Clin 2000;30:383-6.

4. Garces EO, Andrade de Anzambuja MF, da Silva D, Bragatti JA, Jacoby T, Saldanha Thomé F. Renal failure is a risk factor for cefepime-induced encephalopathy.J Nephrol 2008;21:526-34.

5. Thabet F, Al Maghrabi M, Al Barraq A, Tabarki B. Cefepime-induced nonconvulsive status epilepticus: case report and review. Neurocrit Care 2009;10:347-51.

6. Fugate JE, Kalimullah EA, Hocker SE, Clark SL, Wijdicks EF, Rabinstein AA. Cefepime neurotoxicity in the intensive care unit: a cause of severe, underappreciated encephalopathy. Crit Care 2013;17:R264.

7. Sutter R, Rüegg S, Tschudin-Sutter S. Seizures as adverse events of antibiotic drugs: a systematic review. Neurology 2015; 85:1332-41.

8. Bhattacharyya S, Darby RR, Raibagkar P, Gonzalez Castro LN, Berkowitz AL. Antibiotic-associated encephalopathy. Neurology 2016;86:963-71.

9. Appa AA, Jain R, Rakita RM, Hakimian S, Pottinger PS. Char- acterizing cefepime neurotoxicity: a systematic review. Open Forum Infect Dis 2017;4:ofx170.

10. Payne LE, Gagnon DJ, Riker RR, Seder DB, Glisic EK, Morris JG, et al. Cefepime-induced neurotoxicity: a systematic review. Crit Care 2017;21:276.

11. Cho KH. Antibiotics induced seizures and encephalopathy. J Neurocrit Care 2018;11:1-6.

12. Saurina A, Vera M, Pou M, López Pedret J, Darnell A, Campistol JM, et al. Non-convulsive status epilepticus secondary to adjusted cefepime doses in patients with chronic renal failure. Nefrologia 2000;20:554-8.

13. Martínez-Rodríguez JE, Barriga FJ, Santamaria J, Iranzo A, Pareja JA, Revilla M, et al. Nonconvulsive status epilepticus associated with cephalosporins in patients with renal failure. Am J Med 2001;111:115-9.

14. Ferrara N, Abete P, Giordano M, Ferrara P, Carnovale V, Leosco $D$, et al. Neurotoxicity induced by cefepime in a very old hemodialysis patient. Clin Nephrol 2003;59:388-90.

15. De Silva DA, Pan AB, Lim SH. Cefepime-induced encephalopathy with triphasic waves in three Asian patients. Ann Acad Med Singapore 2007;36:450-1.

16. Gangireddy VG, Mitchell LC, Coleman T. Cefepime neurotoxicity despite renal adjusted dosing. Scand J Infect Dis 2011; 43:827-9.

17. Nakagawa R, Sato K, Uesaka Y, Mitsuki T, Kondo K, Wake A, et al. Cefepime-induced encephalopathy in end-stage renal disease patients. J Neurol Sci 2017;376:123-8.

18. Li HT, Lee CH, Wu T, Cheng MY, Tseng WJ, Chang CW, et al. Clinical, electroencephalographic features and prognostic factors of cefepime-induced neurotoxicity: a retrospective study. Neurocrit Care 2019;31:329-37.

19. Capparelli FJ, Diaz MF, Hlavnika A, Wainsztein NA, Leiguarda $\mathrm{R}$, Del Castillo ME. Cefepime- and cefixime-induced encephalopathy in a patient with normal renal function. Neurology 2005;65:1840.

20. Fernández-Torre JL, Martínez-Martínez M, González-Rato J, Maestro I, Alonso I, Rodrigo E, et al. Cephalosporin-induced nonconvulsive status epilepticus: clinical and electroencephalographic features. Epilepsia 2005;46:1550-2.

21. Maganti R, Jolin D, Rishi D, Biswas A. Nonconvulsive status epilepticus due to cefepime in a patient with normal renal function. Epilepsy Behav 2006;8:312-4.

22. Meillier A, Rahimian D. Cefepime-induced encephalopathy with normal renal function. Oxf Med Case Reports 2016; 2016:118-20.

23. U.S. Food and Drug Administration. FDA Drug Safety Communication: cefepime and risk of seizure in patients not receiv- 
ing dosage adjustments for kidney impairment [Internet]. Silver Spring (MD): FDA; 2016 [cited 2019 Dec 16]. Available from: http://www.fda.gov/Drugs/DrugSafety/ucm309661.htm.

24. Ugai T, Morisaki K, Tsuda K, Sugihara H, Nishida Y, Yamakura $\mathrm{M}$, et al. Cefepime-induced encephalopathy in patients with haematological malignancies: clinical features and risk factors. Scand J Infect Dis 2014;46:272-9.

25. Kang JK, Kim SB. Neurotoxicity by cefepime: case-control study.J Neurocrit Care 2014;7:104-10.

26. Lamoth F, Buclin T, Pascual A, Vora S, Bolay S, Decosterd LA, et al. High cefepime plasma concentrations and neurological toxicity in febrile neutropenic patients with mild impairment of renal function. Antimicrob Agents Chemother 2010;54:4360-7.

27. Huwyler T, Lenggenhager L, Abbas M, Ing Lorenzini K, Hughes S, Huttner B, et al. Cefepime plasma concentrations and clinical toxicity: a retrospective cohort study. Clin Microbiol Infect 2017;23:454-9.

28. Boschung-Pasquier L, Atkinson A, Kastner LK, Banholzer S, Haschke M, Buetti N, et al. Cefepime neurotoxicity: thresholds and risk factors: a retrospective cohort study. Clin Microbiol Infect 2019; July 5; https://doi.org/10.1016/j.cmi.2019.06.028.

29. Lacroix C, Kheloufi F, Montastruc F, Bennis Y, Pizzoglio V, Micallef J. Serious central nervous system side effects of cephalosporins: a national analysis of serious reports registered in the French Pharmacovigilance Database. J Neurol Sci 2019;398: 196-201.

30. U.S. Food and Drug Administration. Drug approval package: Maxipime (cefepime hydrochloride) for injection [Internet]. Silver Spring (MD): FDA; 2002 [cited 2019 Dec 16]. Available from: http://www.accessdata.fda.gov/drugsatfda_docs/label/2014/050679s031lbl.pdf.

31. Neftel KA, Cerny A, Cottagnoud P. Cephalosporins. In: Dukes MNG, editors. Meyler's Side Effects of Drugs. 13th ed. Amsterdam: Elsevier; 1996. p. 711-8.

32. Barbhaiya RH, Forgue ST, Gleason CR, Knupp CA, Pittman KA, Weidler DJ, et al. Safety, tolerance, and pharmacokinetic evaluation of cefepime after administration of single intravenous doses. Antimicrob Agents Chemother 1990;34:1118-22.

33. Barbhaiya RH, Knupp CA, Forgue ST, Matzke GR, Guay DR, Pittman KA. Pharmacokinetics of cefepime in subjects with renal insufficiency. Clin Pharmacol Ther 1990;48:268-76.

34. Barbhaiya RH, Knupp CA, Pfeffer M, Zaccardelli D, Dukes GM, Mattern W, et al. Pharmacokinetics of cefepime in patients undergoing continuous ambulatory peritoneal dialysis. Antimicrob Agents Chemother 1992;36:1387-91.

35. U.S. Food and Drug Administration. Cefepime (marketed as Maxipime) update of ongoing safety review [Internet]. Silver
Spring (MD): FDA; 2009 [cited 2019 Dec 16]. Available from: https://www.fda.gov/.

36. Sugimoto M, Uchida I, Mashimo T, Yamazaki S, Hatano K, Ikeda F, et al. Evidence for the involvement of GABA(A) receptor blockade in convulsions induced by cephalosporins. Neuropharmacology 2003;45:304-14.

37. De Sarro A, Ammendola D, Zappala M, Grasso S, De Sarro GB. Relationship between structure and convulsant properties of some beta-lactam antibiotics following intracerebroventricular microinjection in rats. Antimicrob Agents Chemother 1995; 39:232-7.

38. Grill MF, Maganti R. Cephalosporin-induced neurotoxicity: clinical manifestations, potential pathogenic mechanisms, and the role of electroencephalographic monitoring. Ann Pharmacother 2008;42:1843-50.

39. Kim SH, Nam YH, Jeon DS, Lee HW, Nam HJ, Lee SK. Cefepime-induced encephalopathy without renal impairment. Allergy Asthma Respir Dis 2014;2:213-7.

40. Park HM, Noh Y, Yang JW, Shin DH, Lee YB. Cefepime-induced non-convulsive status epilepticus in a patient with normal renal function.J Epilepsy Res 2016;6:97-9.

41. Baek SD, Park SJ, Baek CH, Koo TY, Kang JK, Kim SB. Neurotoxicity induced by cefepime in a patient with minimal change disease. Korean J Nephrol 2010;29:796-801.

42. Lee JY, Kang KP, Kim W, Park SK, Lee S. An overlooked cause of impaired consciousness in a hemodialysis patient. Korean J Intern Med 2012;27:367.

43. Triplett JD, Lawn ND, Chan J, Dunne JW. Cephalosporin-related neurotoxicity: metabolic encephalopathy or non-convulsive status epilepticus? J Clin Neurosci 2019;67:163-6.

44. Fishman RA. Blood-brain and CSF barriers to penicillin and related organic acids. Arch Neurol 1966;15:113-24.

45. Chatellier D, Jourdain M, Mangalaboyi J, Ader F, Chopin C, Derambure $\mathrm{P}$, et al. Cefepime-induced neurotoxicity: an underestimated complication of antibiotherapy in patients with acute renal failure. Intensive Care Med 2002;28:214-7.

46. Durand-Maugard C, Lemaire-Hurtel AS, Gras-Champel V, Hary L, Maizel J, Prud'homme-Bernardy A, et al. Blood and CSF monitoring of cefepime-induced neurotoxicity: nine case reports. J Antimicrob Chemother 2012;67:1297-9.

47. Obermeier B, Daneman R, Ransohoff RM. Development, maintenance and disruption of the blood-brain barrier. Nat Med 2013;19:1584-96.

48. Abanades S, Nolla J, Rodríguez-Campello A, Pedro C, Valls A, Farré M. Reversible coma secondary to cefepime neurotoxicity. Ann Pharmacother 2004;38:606-8.

49. Ryu JA, Lee SM, Kim JI, Lee GH, Lee CM, Song YM, et al. 
Cefepime-induced reversible encephalopathy with triphasic waves in patients with impaired renal function.J Korean Epilepsy Soc 2009; 13:15-8.

50. Seyler L, Cotton F, Taccone FS, De Backer D, Macours P, Vincent JL, et al. Recommended $\beta$-lactam regimens are inadequate in septic patients treated with continuous renal replacement therapy. Crit Care 2011;15:R137.

51. Lam S, Gomolin IH. Cefepime neurotoxicity: case report, pharmacokinetic considerations, and literature review. Pharmacotherapy 2006;26:1169-74.

52. Rhodes NJ, Kuti JL, Nicolau DP, Neely MN, Nicasio AM, Scheetz $\mathrm{MH}$. An exploratory analysis of the ability of a cefepime trough concentration greater than $22 \mathrm{mg} / \mathrm{L}$ to predict neurotoxicity.J Infect Chemother 2016;22:78-83.

53. Hirsch LJ, LaRoche SM, Gaspard N, Gerard E, Svoronos A, Herman ST, et al. American Clinical Neurophysiology Society's standardized critical care EEG terminology: 2012 version. J Clin Neurophysiol 2013;30:1-27.

54. Hartshorn JA, Foreman B. Generalized periodic discharges with triphasic morphology.J Neurocrit Care 2019;12:1-8.

55. Lee S. Pregabalin intoxication-induced encephalopathy with triphasic waves. Epilepsy Behav 2012;25:170-3.

56. Kifune A, Kubota F, Shibata N, Akata T, Kikuchi S. Valproic acid-induced hyperammonemic encephalopathy with triphasic waves. Epilepsia 2000;41:909-12.

57. Dike GL. Triphasic waves in serotonin syndrome.J Neurol Neurosurg Psychiatry 1997;62:200.

58. Hormes JT, Benarroch EE, Rodriguez M, Klass DW. Periodic sharp waves in baclofen-induced encephalopathy. Arch Neurol 1988;45:814-5.

59. Kaplan PW, Birbeck G. Lithium-induced confusional states: nonconvulsive status epilepticus or triphasic encephalopathy? Epilepsia 2006;47:2071-4.

60. Neufeld MY. Periodic triphasic waves in levodopa-induced encephalopathy. Neurology 1992;42:444-6.

61. Lancman ME, Marks S, Mahmood K, Lansen T. Atypical triphasic waves associated with the use of pentobarbital. Electroencephalogr Clin Neurophysiol 1997;102:175-7.

62. de Borchgrave V, Lienard F, Willemart T, van Rijckevorsel K. Clinical and EEG findings in six patients with altered mental status receiving tiagabine therapy. Epilepsy Behav 2003;4:32637.

63. Vulliemoz S, Iwanowski P, Landis T, Jallon P. Levetiracetam accumulation in renal failure causing myoclonic encephalopathy with triphasic waves. Seizure 2009; 18:376-8.

64. Kaplan PW, Sutter R. Affair with triphasic waves-their striking presence, mysterious significance, and cryptic origins: what are they? J Clin Neurophysiol 2015;32:401-5.

65. Beniczky S, Hirsch LJ, Kaplan PW, Pressler R, Bauer G, Aurlien $\mathrm{H}$, et al. Unified EEG terminology and criteria for nonconvulsive status epilepticus. Epilepsia 2013;54 Suppl 6:28-9.

66. Trinka E, Leitinger M. Which EEG patterns in coma are nonconvulsive status epilepticus? Epilepsy Behav 2015;49:203-22.

67. Bauer G, Trinka E. Nonconvulsive status epilepticus and coma. Epilepsia 2010;51:177-90.

68. Young GB, Jordan KG, Doig GS. An assessment of nonconvulsive seizures in the intensive care unit using continuous EEG monitoring: an investigation of variables associated with mortality. Neurology 1996;47:83-9.

69. Lee SJ. A comatose patient with continuous generalized $3 \mathrm{~Hz}$ spike-and-wave discharges after cardiac arrest. J Korean Neurol Assoc 2015;33:209-12.

70. Bragatti JA, Rossato R, Ziomkowski S, Kliemann FA. Cefepime-induced encephalopathy: clinical and electroencephalographic features in seven patients. Arq Neuropsiquiatr 2005; 63:87-92.

71. Sonck J, Laureys G, Verbeelen D. The neurotoxicity and safety of treatment with cefepime in patients with renal failure. Nephrol Dial Transplant 2008;23:966-70.

72. Lin CJ, Chen SP, Wang SJ, Fuh JL. Cefepime-related encephalopathy in peritoneal dialysis patients. J Chin Med Assoc 2011; 74:87-90.

73. Shirota Y, Ohtomo R, Hanajima R, Terao Y, Tsutsumi R, Tsuji S. Severely abnormal electroencephalogram in two patients who were treated with cefepime. Rinsho Shinkeigaku 2012;52:356-9.

74. Mani LY, Kissling S, Viceic D, Vogt B, Burnier M, Buclin T, et al. Intermittent hemodialysis treatment in cefepime-induced neurotoxicity: case report, pharmacokinetic modeling, and review of the literature. Hemodial Int 2015;19:333-43.

75. Toda Y, Yamazaki M, Ota T, Fujisawa Y, Kimura K. A case of cefepime encephalopathy, being difficult to distinguish from non-convulsive status epilepticus during the treatment of bacterial meningitis. Rinsho Shinkeigaku 2016;56:678-83.

76. Tchapyjnikov D, Luedke MW. Cefepime-induced encephalopathy and nonconvulsive status epilepticus: dispelling an artificial dichotomy. Neurohospitalist 2019;9:100-4.

77. Dixit S, Kurle P, Buyan-Dent L, Sheth RD. Status epilepticus associated with cefepime. Neurology 2000;54:2153-5.

78. Chow KM, Wang AY, Hui AC, Wong TY, Szeto CC, Li PK. Nonconvulsive status epilepticus in peritoneal dialysis patients. Am J Kidney Dis 2001;38:400-5.

79. Plensa E, Gallardo E, Ribera JM, Batlle M, Oriol A, Costa J. Nonconvulsive status epilepticus associated with cefepime in a patient undergoing autologous stem cell transplantation. Bone 
Marrow Transplant 2004;33:119-20.

80. Primavera A, Cocito L, Audenino D. Nonconvulsive status epilepticus during cephalosporin therapy. Neuropsychobiology 2004;49:218-22.

81. Chang YM. Cefepime-induced nonconvulsive status epilepticus as a cause of confusion in an elderly patient. J Formos Med Assoc 2015; 114:290-1.

82. Suarez-de-la-Rica A, Hernández-Gancedo C, López-Tofiño A, Maseda E, Gilsanz F. Severe cefepime-induced status epilepticus treated with haemofiltration. Rev Esp Anestesiol Reanim 2016;63:353-6.

83. Bora I, Demir AB, Uzun P. Nonconvulsive status epilepticus cases arising in connection with cephalosporins. Epilepsy Behav Case Rep 2016;6:23-7.

84. Anuhya V, Kunder SK, Madhyastha S, Nayak V, Acharya RV, Ramamoorthi $\mathrm{K}$, et al. Looking beyond the obvious: cefepime-induced nonconvulsive status epilepticus. J Pharmacol Pharmacother 2017;8:145-7.

85. Fountain NB, Waldman WA. Effects of benzodiazepines on triphasic waves: implications for nonconvulsive status epilepticus.
J Clin Neurophysiol 2001;18:345-52.

86. Brigo F, Storti M. Triphasic waves. Am J Electroneurodiagnostic Technol 2011;51:16-25.

87. Malone RS, Fish DN, Abraham E, Teitelbaum I. Pharmacokinetics of cefepime during continuous renal replacement therapy in critically ill patients. Antimicrob Agents Chemother 2001; 45:3148-55.

88. Kim A, Kim JE, Paek YM, Hong KS, Cho YJ, Cho JY, et al. Cefepime- induced non-convulsive status epilepticus (NCSE). J Epilepsy Res 2013;3:39-41.

89. Kwon J, Choi JY, Bae EK. Cefepime-induced aphasic status epilepticus mimicking acute stroke. J Epilepsy Res 2014;4:85-7.

90. Lee GH. Cefepime induced non-convulsive status epilepticus (NCSE). J Pusan Natl Univ Hosp 2014;36:185-9.

91. Yahav D, Paul M, Fraser A, Sarid N, Leibovici L. Efficacy and safety of cefepime: a systematic review and meta-analysis. Lancet Infect Dis 2007;7:338-48.

92. Kim PW, Wu YT, Cooper C, Rochester G, Valappil T, Wang Y, et al. Meta-analysis of a possible signal of increased mortality associated with cefepime use. Clin Infect Dis 2010;51:381-9. 